\title{
Laparoscopic total extraperitneal hernia repair outcomes in recurrent inguinal hernia
}

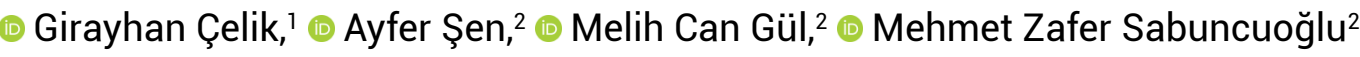 \\ 'Department of General Surgery, Isparta City Hospital, Isparta, Turkey \\ 2Department of General Surgery, Süleyman Demirel University Faculty of Medicine, Isparta, Turkey
}

\begin{abstract}
Introduction: Inguinal hernia repair is one of the common procedures in surgical daily routine. The aim of this study was to present clinical outcomes and reccurency rates of laparoscopic total extraperitoneal hernia repair in recurrent inguinal hernia performed in our clinic.

Materials and Methods: The data of patients who underwent laparoscopic total extraperitoneal herniorraphy between January 2012 and May 2018 were evaluated retrospectively.

Results: 23 patients who underwent laparoscopic total extraperitoneal herniorraphy were included in this study. Mean age of the patients was 58.65. 12 patients were performed from left, 9 patients from right, 2 patients were performed bilaterally. Mean duration of the operation was 35 minutes, mean duration of hospitalization was 1 day.

Conclusion: While planning surgical technique for recurrent inguinal hernia; if previous surgery was performed with anterior approach, posterior approach should be chosen, and vice versa.

Keywords: Hernia; inguinal; laparoscopic total extraperitoneal; recurrent.
\end{abstract}

\section{Introduction}

75 percent of abdominal Wall hernias occurs in inguinal region. Male to female ratio is $7 / 1$. The prevelance of inguinal hernia is approximately $3-8 \%$ percent of the population. ${ }^{[1]}$ İnuinal hernia is a disease with a lifetime risk ratio of $27 \%$ in men and 3\% in women. However the recurrence rates of these hernias are $11 \%$ in men, $3 \%$ in women. Because of the high incidence of this disease, inguinal hernia reparing is the most common procedure in the general surgery and is $10-15 \%$ of all operations. ${ }^{[2]}$ After starting the mesh usage for inguinal hernia repairment, recurrence rates decreased dramatically. In guidelines, Lichtenstein oper- ation is considered to be the reference technique. ${ }^{[3]}$ Recurrence rate is found $0-7.7 \%$ at 2 years follow up. ${ }^{[3,4]}$ An alternative treatment aproach should be prefered in recurrent inguinal hernias which were repaired with mesh. Laparoscopic posterior approach techniques such as Total Extraperitoneal (TEP) or Transabdominal Peritoneal (TAPP), should be prefered for Recurrent inguinal hernias, which were repaired with anterior approach such as Lichtenstein. ${ }^{[5]}$ After the laparoscopic surgery has been performed in inguinal hernia repairs, hernia surgery has gained a different meaning and these laparoscopic techniques have become accepted all around the world in a short time and applied 
successfully in many centers. Laparoscopic Total Exstraperitoneal (TEP) inguinal hernia repair is a tension-free method as well as having general advantages of laparoscopic surgery such as minimal postoperative pain, short recovery time and good cosmetic outcomes. ${ }^{[6]}$ In addition, the use of a previously unexposed area in recurrence after anterior operation usage makes the operation relatively easier. The aim of this study is to evaluate our experience in laparoscopic Total Extraperitoneal Hernia method in the treatment of recurrent inguinal hernia in Suleyman Demirel University Faculty of Medicine, Isparta.

\section{Materials and Methods}

The data of patients who underwent laparoscopic total extraperitoneal herniorraphy between January 2012 and May 2018 were analyzed retrospectively.

Surgical Technique: In all patients, intratracheal entubation was performed in supine position, urinary cathater placement was inserted and processing started. The primer surgeon was placed in the opposite the side of the hernia and second surgeon was on the opposite side of surgeon. 1.5 centimeter transverse skin incision which is just below the umblicus, was performed and skin subcutaeneus tissue and the upper leaf of rectus fascia were passed through. Just above the semilunar line, the preperitoneal area was entered by the $10 \mathrm{~mm}$ trochar on the lower leaf of the rectus. The preperitoneal area was dissected by moving $14 \mathrm{mmHg}$ gas through the medial, lateral and posterior directions until the periperitoneal area was seen. Another $5 \mathrm{~mm}$ trocar was inserted $5 \mathrm{~cm}$ above the suprapubic area. And another $5 \mathrm{~mm}$ trocar was inserted between these trocars. Inguinal region was dissected and herniated structures were pulled downwards and released by sharp and blunt with dissection. Hernial sac was revealed and all adhesions around the pouch were seperated into peritoneum and if the patient is male spermatic cord was deperitonised. Dissection was continued until spina iliaca anterior superior in lateral site, and was crossed the medial line, and fell under the Cooper ligament's inferior. Anatomic mesh of appropriate size was placed so that the aperture was closed. And then the mesh was fixed by placing the tacher. Pressure was decreased slowly and mesh was checked and gas was totally drained. Skin incisions were sutured with $3 / 0$ prolene suture.

\section{Results}

In our clinic total of 202 patients were operated for inguinal hernia with TEP technique and 87 of these operations were bilateral, 61 right, 54 left, 23 of them were recurrent inguinal hernia. Mean age of patients treated with TEP herniorrhaphy technique was 58.65 (22-86). 17 patients were operated once, 4 patients twice, 1 patient 3 times, 1 patient was seven times operated previously. In the early postoperative period, seroma, hydrocele, hematoma and testical ischemia were not occurred. Also no major complications or mortality were occurred. All patients were called for follow up between 1 to 13 months. 12 patients were performed from left, 9 patients from right, 2 patients were performed bilaterally. Mean duration of the operation was 35 minutes, mean duration of hospitalization was 1 day (Table 1 ).

\section{Discussion}

Lichtenstein's technique (tension-free inguinal hernia repairment with mesh) decreased rates of recurrency. However, in some patients recurrence may also be seen after Lichtenstein's. ${ }^{[3,7]}$ This rate was found to be lower in the repair of recurrent hernia by TEP method and it was reported as $0 \%$ in some studies. ${ }^{[8-10]}$ In our clinic, this ratio was $0 \%$. Lowham et al. ${ }^{[10]}$ indicated that recurrence after laparoscopic TEP herniography is due to technique such as inappropriate dissection, wrong prothesis size, inappropriate positioning of the mesh. Schumpelick et al. ${ }^{[1]]}$ indicates that recurrence rates of modern inguinal hernia repairs are $1-3 \%$ in primary and 3-5\% in recurrent. Lau et al. ${ }^{[12]}$ indicates that high recurrence rate of direct inguinal hernia was caused by inappropriate technique, strain in

Table 1. Demographic data of patients and cases

\begin{tabular}{lcc} 
Operation & $\mathbf{n}$ & $\%$ \\
\hline Gender & & \\
$\quad$ Female & 2 & 8.6 \\
$\quad$ Male & 21 & 91.4 \\
Recurrence & & \\
1 & 17 & 73.9 \\
2 & 4 & 17.4 \\
3 & 1 & 4.3 \\
7 & 1 & 4.3 \\
Hernia site & & \\
Right & 9 & 39.1 \\
Left & 12 & 52.1 \\
Bilateral & 2 & 8.6 \\
Symptom & & \\
Swelling & 5 & 21.7 \\
Pain & 10 & 43.4 \\
Swelling and pain & 8 & 34.8 \\
\hline
\end{tabular}


restoration site and inadequate support of posterior wall with suture herniorrhaphy. Many articles showed that the potential reasons of indirect hernia were unaccomplished disection or sac dissection was performed inferiorly or inadequate restoration of internal ring. ${ }^{[13-14]}$ Yoon et al. ${ }^{[15]}$ indicates that direct hernia was more common than indirect hernia in recurrent hernia group, but also states that further research is needed because data of previous operation's type that the operation was performed either with suture technique or Lichtenstein's. TEP especially in recurrent cases with multiple anterior operations should be considered because preperitoneal area was free from tissue damage and scar tissue of previous operations, embracing advantages of laparoscopic surgery and lower recurrence rates. Posterior approach techniques has increasing popularity among surgeons because of easy access to preperitoneal area from lateral site of rectus muscle and rectus sheath. This approach provides an easy and a clear view of the anatomical hernia areas.

\section{Conclusion}

It is important that; the previous operation is performed with an anterior or posterior approach while the surgery to be performed in the recurrent inguinal hernia. Recurrence rate decreased after anterior approaches using mesh such as Lichtenstein's technique. However, recurrence may also be observed in some patients with Lichtenstein's operation. Posterior approach should be considered in recurrence after this operations. Thus, complications such as vascular injury, nerve injury, increased inflammatory reaction caused by secondary operation may be avoided. If the posterior approach performed by experienced surgeons, the development of these complications is prevented. In the same way, If previous operation was performed by using posterior approach; anterior approach should be considered. Laparoscopic Inguinal Hernia repair is an advanced laparoscopic technique. The laparoscopic hernia operation in advenced laparoscopic hernia group, besides the negative sides such such as the long learning curve and high cost, can be advantageous to open surgery with its advantages such as aesthetic apperances, early mobilisation. Especially in recurrences after anterior approach, TEP can be considered advantageous because it is easier to be performed and has lower recurrence rates.

Peer-review: Externally peer-reviewed.
Conflict of Interest: None declared.

\section{References}

1. Kingsnorth AN, Gray MR, Nott DM. Prospective randomized trial comparing the Shouldice technique and plication darn for inguinal hernia. Br J Surg 1992;79:1068-70. [CrossRef]

2. Schumpelick $\mathrm{V}$, Treutner $\mathrm{KH}$, Arlt $\mathrm{G}$. Inguinal hernia repair in adults. Lancet 1994;344:375-9. [CrossRef]

3. Simons MP, Aufenacker T, Bay-Nielsen M, Bouillot JL, Campanelli G, Conze J, et al. European Hernia Society guidelines on the treatment of inguinal hernia in adult patients. Hernia 2009;13:343-403. [CrossRef]

4. Burcharth J, Pommergaard HC, Bisgaard T, Rosenberg J. Patient-related risk factors for recurrence after inguinal hernia repair: a systematic review and meta-analysis of observational studies. Surg Innov 2015;22:303-17. [CrossRef]

5. Bökkerink WJ, Persoon AM, Akkersdijk WL, van Laarhoven CJ, Koning GG. The TREPP as alternative technique for recurrent inguinal hernia after Lichtenstein's repair: A consecutive case series. Int J Surg 2017;40:73-7. [CrossRef]

6. Wang WJ, Chen JZ, Fang Q, Li JF, Jin PF, Li ZT. Comparison of the effects of laparoscopic hernia repair and Lichtenstein tension-free hernia repair. J Laparoendosc Adv Surg Tech A 2013;23:301-5. [CrossRef]

7. Keus F, Wetterslev J, Gluud C, van Laarhoven CJ. Evidence at a glance: error matrix approach for overviewing available evidence. BMC Med Res Methodol 2010;10:90. [CrossRef]

8. Scheuerlein $\mathrm{H}$, Schiller A, Schneider $\mathrm{C}$, Scheidbach $\mathrm{H}$, Tamme $C$, Köckerling F. Totally extraperitoneal repair of recurrent inguinal hernia. Surg Endosc 2003;17:1072-6. [CrossRef]

9. Garg P, Menon GR, Rajagopal M, Ismail M. Laparoscopic total extraperitoneal repair of recurrent inguinal hernias. Surg Endosc 2010;24:450-4. [CrossRef]

10. Lowham AS, Filipi CJ, Fitzgibbons RJ Jr, Stoppa R, Wantz $\mathrm{GE}$, Felix EL, et al. Mechanisms of hernia recurrence after preperitoneal mesh repair. Traditional and laparoscopic. Ann Surg 1997;225:422-31. [CrossRef]

11. Schumpelick V, Kupczyk-Joeris D, Töns C, Pfingsten FP. [Repair of recurrent inguinal hernia. Tactics, technic and results]. Chirurg 1990;61:526-9.

12. Lau $\mathrm{H}$. Endoscopic totally extraperitoneal inguinal hernioplasty for recurrence after open repair. ANZ J Surg 2004;74:877-80. [CrossRef]

13. Postlethwait RW. Recurrent inguinal hernia. Ann Surg 1985;202:777-9. [CrossRef]

14. Weinstein $M$, Roberts $M$. Recurrent inguinal hernia. Follow-up study of 100 postoperative patients. Am J Surg 1975;129:564-9. [CrossRef]

15. Yoon Young Choi, Zisun Kim, and Kyung Yul Hur.Journal of Laparoendoscopic \& Advanced Surgical Techniques.Jul 2010.ahead of printhttp://doi.org/10.1089/lap.2010.00. 